\title{
Edoxaban versus Warfarin for the Treatment of Symptomatic Venous Thromboembolism
}

\author{
The Hokusai-VTE Investigators*
}

\section{A BSTRACT}

\begin{abstract}
The members of the writing committee (Harry R. Büller, M.D., Hervé Décousus, M.D., Michael A. Grosso, M.D., Michele Mercuri, M.D., Saskia Middeldorp, M.D., Martin H. Prins, M.D., Gary E. Raskob, Ph.D., Sebastian M. Schellong, M.D., Lee Schwocho, Ph.D., Annelise Segers, M.D., Minggao Shi, Ph.D., Peter Verhamme, M.D., and Phil Wells, M.D.) assume responsibility for the content and integrity of the article. Address reprint requests to $\mathrm{Dr}$. Büller at the Department of Vascular Medicine, Academic Medical Center, F4-275, Meibergdreef 9, 1105 AZ Amsterdam, the Netherlands, or at h.r.buller@amc.uva.nl.

*The affiliations of the authors (members of the writing committee) are listed in the Appendix. The investigators participating in the Hokusai-VTE study and the study committees are listed in the Supplementary Appendix, available at NEJM.org.
\end{abstract}

This article was published on September 1 , 2013 , and updated on January 2, 2014, at NEJM.org.

N EnglJ Med 2013;369:1406-15. DOI: 10.1056/NEJMoal306638

Copyright @ 2013 Massachusetts Medical Society.

\section{BACKGROUND}

Whether the oral factor Xa inhibitor edoxaban can be an alternative to warfarin in patients with venous thromboembolism is unclear.

\section{METHODS}

In a randomized, double-blind, noninferiority study, we randomly assigned patients with acute venous thromboembolism, who had initially received heparin, to receive edoxaban at a dose of $60 \mathrm{mg}$ once daily, or $30 \mathrm{mg}$ once daily (e.g., in the case of patients with creatinine clearance of 30 to $50 \mathrm{ml}$ per minute or a body weight below $60 \mathrm{~kg}$ ), or to receive warfarin. Patients received the study drug for 3 to 12 months. The primary efficacy outcome was recurrent symptomatic venous thromboembolism. The principal safety outcome was major or clinically relevant nonmajor bleeding.

\section{RESULTS}

A total of 4921 patients presented with deep-vein thrombosis, and 3319 with a pulmonary embolism. Among patients receiving warfarin, the time in the therapeutic range was $63.5 \%$. Edoxaban was noninferior to warfarin with respect to the primary efficacy outcome, which occurred in 130 patients in the edoxaban group (3.2\%) and 146 patients in the warfarin group (3.5\%) (hazard ratio, 0.89; 95\% confidence interval $[\mathrm{CI}], 0.70$ to $1.13 ; \mathrm{P}<0.001$ for noninferiority). The safety outcome occurred in 349 patients (8.5\%) in the edoxaban group and 423 patients $(10.3 \%)$ in the warfarin group (hazard ratio, $0.81 ; 95 \% \mathrm{CI}, 0.71$ to $0.94 ; \mathrm{P}=0.004$ for superiority). The rates of other adverse events were similar in the two groups. A total of $938 \mathrm{pa}-$ tients with pulmonary embolism had right ventricular dysfunction, as assessed by measurement of N-terminal pro-brain natriuretic peptide levels; the rate of recurrent venous thromboembolism in this subgroup was 3.3\% in the edoxaban group and $6.2 \%$ in the warfarin group (hazard ratio, $0.52 ; 95 \%$ CI, 0.28 to 0.98 ).

\section{CONCLUSIONS}

Edoxaban administered once daily after initial treatment with heparin was noninferior to high-quality standard therapy and caused significantly less bleeding in a broad spectrum of patients with venous thromboembolism, including those with severe pulmonary embolism. (Funded by Daiichi-Sankyo; Hokusai-VTE ClinicalTrials.gov number, NCT00986154.) 
ENOUS THROMBOEMBOLISM IS THE THIRD most common cardiovascular disease after myocardial infarction and stroke, affecting at least 700,000 persons annually in North America. ${ }^{1-3}$ The standard treatment consists of low-molecularweight heparin followed by vitamin K antagonists. ${ }^{4}$ A number of studies have established that new oral anticoagulants with or without initial heparin therapy are effective alternatives. ${ }^{5-8}$

Edoxaban is a direct inhibitor of activated factor $\mathrm{X}$ with a rapid onset of action. It is administered orally once daily and has proven antithrombotic efficacy. ${ }^{9-11}$ The Hokusai-VTE study was a randomized, double-blind clinical trial that was conducted to evaluate edoxaban for the treatment of venous thromboembolism. The study was designed with the aim of broadening applicability to real-world practice and encouraging the enrollment of all patients, including those with extensive disease, by specifying that treatment should be initiated with the proven, global standard of parenteral heparin; that the dose of the study drug should be halved in patients perceived to be at higher risk for bleeding (e.g., those with renal impairment or low body weight); and that physicians should be allowed to adjust the duration of treatment after 3 months according to their clinical judgment or in keeping with evolving evidence. In addition, patients were followed for 12 months regardless of the duration of therapy to compare the clinical outcomes of the two study regimens.

\section{METHODS}

\section{STUDY OVERSIGHT}

In this randomized, double-blind trial, we compared heparin (enoxaparin or unfractionated heparin) followed by edoxaban with heparin followed by warfarin with respect to efficacy and safety in patients with deep-vein thrombosis, pulmonary embolism, or both. ${ }^{12}$ A coordinating committee in collaboration with the sponsor (Daiichi Sankyo) was responsible for the design and oversight of the study and for developing the protocol. The institutional review board at each participating center approved the protocol. All patients provided written informed consent. The sponsor was responsible for the collection and maintenance of the data. An independent committee, whose members were unaware of the study-group assignments, adjudicated all suspected outcomes and the results of baseline imaging tests and assessed the anatomical extent of thrombosis. An independent data and safety monitoring committee periodically reviewed study outcomes. The members of the writing committee wrote all drafts of the manuscript (no one who is not a named author contributed substantially to the manuscript), verified the data, and vouch for the completeness of the data, the accuracy of the analyses, and the fidelity of the study to the protocol. The protocol and accompanying documents are available with the full text of this article at NEJM.org.

\section{PATIENTS}

Patients 18 years of age or older were eligible if they had objectively diagnosed, acute, symptomatic deep-vein thrombosis involving the popliteal, femoral, or iliac veins or acute, symptomatic pulmonary embolism (with or without deep-vein thrombosis). Patients were excluded if they had contraindications to heparin or warfarin, had received treatment for more than 48 hours with therapeutic doses of heparin, had received more than one dose of a vitamin $\mathrm{K}$ antagonist, had cancer for which long-term treatment with lowmolecular-weight heparin was anticipated, had another indication for warfarin therapy, continued to receive treatment with aspirin at a dose of more than $100 \mathrm{mg}$ daily or dual antiplatelet therapy, or had creatinine clearance of less than $30 \mathrm{ml}$ per minute. The full list of exclusion criteria is provided in the protocol.

\section{RANDOMIZATION AND STUDY TREATMENT}

Randomization was performed with the use of an interactive Web-based system, with stratification according to the qualifying diagnosis (deepvein thrombosis or pulmonary embolism), presence or absence of temporary risk factors, and the dose of edoxaban. All patients received initial therapy with open-label enoxaparin or unfractionated heparin for at least 5 days. ${ }^{12}$ Edoxaban or warfarin was administered in a double-blind, double-dummy fashion.

Edoxaban (or placebo) was started after discontinuation of initial heparin. Edoxaban was administered at a dose of $60 \mathrm{mg}$ orally once daily, taken with or without food, or at a dose of $30 \mathrm{mg}$ once daily in patients with a creatinine clearance of 30 to $50 \mathrm{ml}$ per minute or a body weight of $60 \mathrm{~kg}$ or less or in patients who were receiving concomitant treatment with potent P-glycoprotein inhibitors.

Warfarin (or placebo) was started concurrently 
with the study regimen of heparin, with adjustment of the dose to maintain the international normalized ratio (INR) between 2.0 and 3.0. All measurements were performed by means of a point-of-care device that provided an actual INR value for patients receiving warfarin and a sham INR value for patients receiving edoxaban. ${ }^{12}$ INR measurements were required to be performed at least monthly.

Treatment with edoxaban or warfarin was to be continued for at least 3 months in all patients and for a maximum of 12 months. The duration was determined by the treating physician on the basis of the patient's clinical features and patient preference.

\section{OUTCOME MEASURES}

The primary efficacy outcome was the incidence of adjudicated symptomatic recurrent venous thromboembolism, which was defined as a composite of deep-vein thrombosis or nonfatal or fatal pulmonary embolism. Death was adjudicated as related to venous thromboembolism, other cardiovascular disease, bleeding, or other causes. Pulmonary embolism was considered to be the cause of death if there was objective documentation that a pulmonary embolism caused the death or if the death could not be attributed to a documented cause and pulmonary embolism could not be ruled out. Prespecified secondary efficacy outcomes included the primary efficacy outcome combined with either death from cardiovascular causes or death from any cause.

The principal safety outcome was the incidence of adjudicated clinically relevant bleeding, which was defined as a composite of major or clinically relevant nonmajor bleeding. Bleeding was defined as major if it was overt and was associated with a decrease in hemoglobin of $2 \mathrm{~g}$ per deciliter or more or required a transfusion of 2 or more units of blood, occurred in a critical site, or contributed to death. ${ }^{13}$ Clinically relevant nonmajor bleeding was defined as overt bleeding that did not meet the criteria for major bleeding but was associated with the need for medical intervention, contact with a physician, or interruption of the study drug or with discomfort or impairment of activities of daily life. ${ }^{14}$ Net clinical benefit was determined on the basis of the composite of symptomatic recurrent venous thromboembolism or major bleeding. The criteria for adjudication of outcomes are provided in the Supplementary Appendix, available at NEJM.org.

\section{SURVEILLANCE AND FOLLOW-UP}

Patients underwent assessment, in the clinic or by telephone, on days 5 through 12,30 , and 60 after randomization and monthly thereafter while they were taking the study drug or every 3 months after discontinuing the study drug. All patients were to be contacted at month 12. Patients were instructed to report symptoms suggestive of recurrent venous thromboembolism or bleeding. Appropriate diagnostic testing, laboratory testing, or both were required in patients with suspected events.

\section{STATISTICAL ANALYSIS}

The study was designed as an event-driven trial to test the hypothesis that edoxaban would be noninferior to warfarin with respect to the primary efficacy outcome, with an upper limit of the confidence interval for the hazard ratio of 1.5 and a two-sided alpha level of 0.05 . This margin corresponds to retention of at least $70 \%$ of the treatment effect of warfarin.

Assuming equal efficacy of edoxaban and warfarin, we estimated that 220 events would need to occur for the study to have $85 \%$ power to show the noninferiority of edoxaban. When we determined that the targeted number of events was expected to be accrued, we set the date for concluding the study (study closure) such that the last patient who underwent randomization would complete 6 months of study treatment and follow-up. Assuming a 3\% incidence of the primary efficacy outcome, we estimated that we would have to enroll at least 7500 patients.

All efficacy analyses were performed in the modified intention-to-treat population, which included all patients who underwent randomization and received at least one dose of the study drug. The primary analysis included all efficacy outcomes from randomization through the end of 12 months or study closure (overall study period), regardless of the duration of the patient's study treatment. The time to the first primary efficacy outcome was analyzed with the use of a Cox proportional-hazards model with stratification factors as covariates. In addition, the primary efficacy outcome was evaluated for the on-treatment period - the time during which the patients were receiving the study drug or within 3 days after the study drug was stopped or interrupted.

Analyses of bleeding outcomes included patients who received at least one dose of the study drug 
(safety population). The time to clinically relevant bleeding during the on-treatment period was compared with the use of the same Cox proportionalhazards model that was used for the primary efficacy outcome. Time-to-event curves were calculated with the use of the Kaplan-Meier method.

Prespecified subgroup analyses were performed in subgroups defined according to the qualifying diagnosis and according to status with respect to right ventricular dysfunction (evidence or no evidence) in patients with pulmonary embolism. The time in the therapeutic INR range was calculated with the use of standard methods, ${ }^{15}$ with the initial heparin lead-in period not included and with correction for planned interruptions. In all patients with pulmonary embolism, N-terminal pro-brain natriuretic peptide (NT-proBNP) levels were measured at baseline (morning sample) in a core laboratory. Right ventricular dysfunction was defined as an NT-proBNP level of 500 pg per milliliter or higher. ${ }^{16,17}$ In addition, an independent reviewer who was unaware of the treatment assignments evaluated right ventricular dimensions on the qualifying computed tomographic scan in a random sample of 1002 patients. Right ventricular dysfunction was defined as the ratio of right ventricular diameter to left ventricular diameter of 0.9 or more. ${ }^{18,19}$

\section{RESULTS}

\section{PATIENTS AND TREATMENT}

From January 2010 through October 2012, a total of 8292 patients were enrolled at 439 centers in 37 countries (Fig. 1). The baseline characteristics of the patients were similar in the two study groups (Table 1). The median duration of heparin treatment after randomization was 7 days. Details of the actual duration of treatment with the study drug are provided in Table S2 in the Supplementary Appendix; $40 \%$ of patients were treated for 12 months. Adherence to edoxaban treatment was $80 \%$ or more in $99 \%$ of the patients in that group. Among patients receiving warfarin, the INR was in the therapeutic range for $63.5 \%$ of the time, above 3.0 for $17.6 \%$ of the time, and below 2.0 for $18.9 \%$ of the time.

\section{RECURRENT VENOUS THROMBOEMBOLISM}

A recurrence of venous thromboembolism during the overall study period occurred in 130 of 4118 patients (3.2\%) in the edoxaban group and in 146 of 4122 patients (3.5\%) in the warfarin group (hazard ratio with edoxaban, 0.89; $95 \%$ confidence interval [CI], 0.70 to $1.13 ; \mathrm{P}<0.001$ for noninferiority). The difference in risk (edoxaban minus warfarin) was -0.39 percentage points (95\% CI, -1.16 to 0.39 ). The types and time

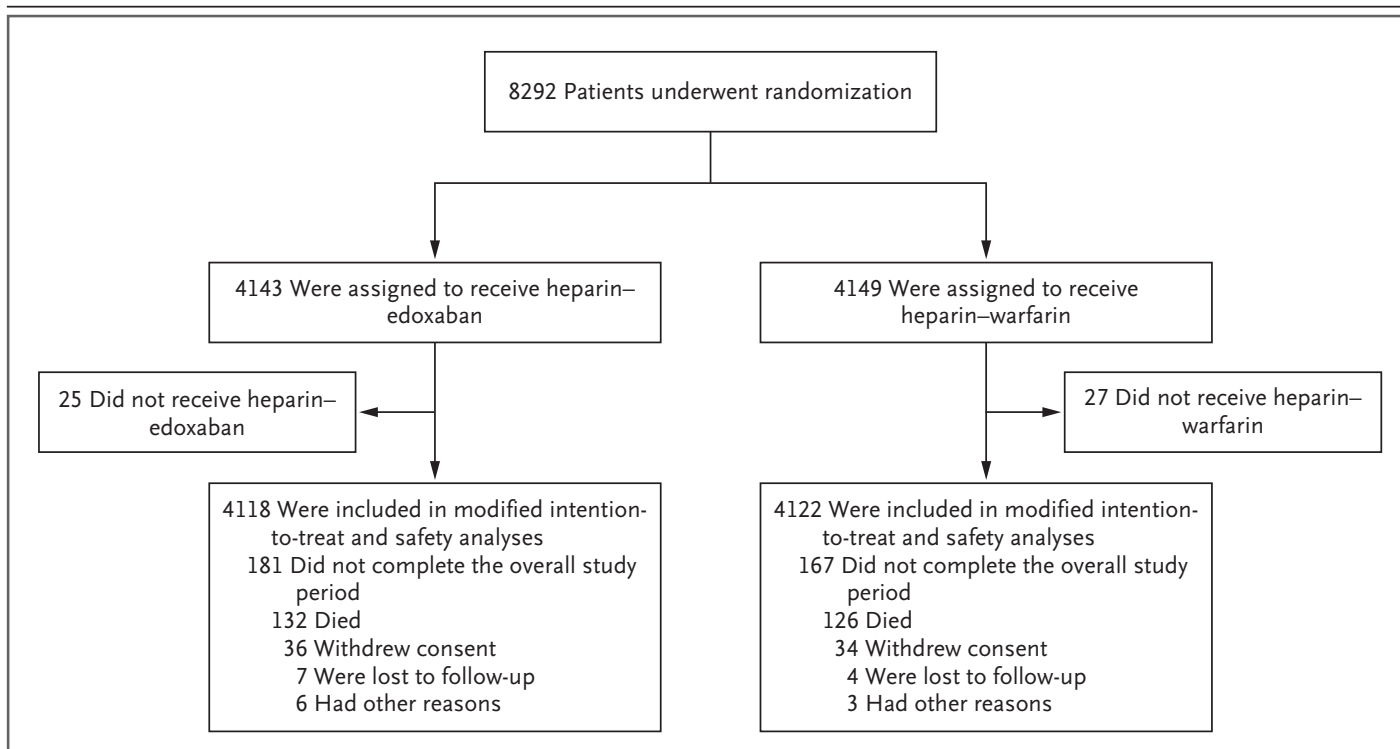

Figure 1. Randomization and Follow-up.

The modified intention-to-treat and safety analyses included all patients who underwent randomization and received at least one dose of the study drug. 


\begin{tabular}{|c|c|c|c|c|c|c|}
\hline \multirow[t]{2}{*}{ Characteristic } & \multicolumn{2}{|c|}{ All Patients } & \multicolumn{2}{|c|}{$\begin{array}{c}\text { Patients with } \\
\text { Deep-Vein Thrombosis Only }\end{array}$} & \multicolumn{2}{|c|}{$\begin{array}{c}\text { Patients with } \\
\text { Pulmonary Embolism }\end{array}$} \\
\hline & $\begin{array}{l}\text { Edoxaban } \\
(\mathrm{N}=4118)\end{array}$ & $\begin{array}{l}\text { Warfarin } \\
(\mathrm{N}=4122)\end{array}$ & $\begin{array}{l}\text { Edoxaban } \\
(\mathrm{N}=2468)\end{array}$ & $\begin{array}{l}\text { Warfarin } \\
(\mathrm{N}=2453)\end{array}$ & $\begin{array}{l}\text { Edoxaban } \\
(\mathrm{N}=1650)\end{array}$ & $\begin{array}{l}\text { Warfarin } \\
(\mathrm{N}=1669)\end{array}$ \\
\hline \multicolumn{7}{|l|}{ Age } \\
\hline Mean - yr & $55.7 \pm 16.3$ & $55.9 \pm 16.2$ & $54.7 \pm 16.0$ & $54.9 \pm 15.9$ & $57.1 \pm 16.6$ & $57.4 \pm 16.5$ \\
\hline$\geq 75 \mathrm{yr}-$ no. (\%) & $560(13.6)$ & $544(13.2)$ & $282(11.4)$ & $273(11.1)$ & $278(16.8)$ & $271(16.2)$ \\
\hline Male sex — no. (\%) & $2360(57.3)$ & $2356(57.2)$ & $1497(60.7)$ & $1481(60.4)$ & $863(52.3)$ & $875(52.4)$ \\
\hline \multicolumn{7}{|l|}{ Weight — no. (\%) } \\
\hline$\leq 60 \mathrm{~kg} \dagger$ & $524(12.7)$ & $519(12.6)$ & $320(13.0)$ & $304(12.4)$ & $204(12.4)$ & 215 (12.9) \\
\hline$>100 \mathrm{~kg}$ & $611(14.8)$ & $654(15.9)$ & $360(14.6)$ & $379(15.5)$ & $251(15.2)$ & $275(16.5)$ \\
\hline $\begin{array}{l}\text { Creatinine clearance } \geq 30 \text { to } \leq 50 \mathrm{ml} / \\
\min -\text { no. }(\%) \dagger\end{array}$ & $268(6.5)$ & $273(6.6)$ & $152(6.2)$ & $153(6.2)$ & $116(7.0)$ & $120(7.2)$ \\
\hline $\begin{array}{l}\text { Patients receiving } 30 \mathrm{mg} \\
\text { of edoxaban at randomiza- } \\
\text { tion - no. }(\%) \dagger\end{array}$ & $733(17.8)$ & $719(17.4)$ & $425(17.2)$ & $411(16.8)$ & $308(18.7)$ & $308(18.5)$ \\
\hline \multicolumn{7}{|l|}{$\begin{array}{l}\text { Anatomical extent of qualifying event } \\
\qquad \text { no. (\%) } \%\end{array}$} \\
\hline Limited & - & - & $603(24.4)$ & $596(24.3)$ & $128(7.8)$ & $123(7.4)$ \\
\hline Intermediate & - & - & $795(32.2)$ & $773(31.5)$ & $679(41.2)$ & $682(40.9)$ \\
\hline Extensive & - & - & 1035 (41.9) & $1049(42.8)$ & $743(45.0)$ & $778(46.6)$ \\
\hline Not assessable & - & - & $35(1.4)$ & $35(1.4)$ & $100(6.1)$ & $86(5.2)$ \\
\hline Concomitant DVT — no. (\%) & - & - & - & - & $410(24.8)$ & $404(24.2)$ \\
\hline \multicolumn{7}{|l|}{ Baseline NT-proBNP — no. (\%) } \\
\hline Patients with measurement & - & - & - & - & $1484(89.9)$ & $1505(90.2)$ \\
\hline Patients with level $\geq 500 \mathrm{pg} / \mathrm{ml}$ & - & - & - & - & $454(27.5)$ & $484(29.0)$ \\
\hline $\begin{array}{l}\text { Right ventricular dysfunction } \\
- \text { no./total no. (\%)』 }\end{array}$ & - & - & - & - & $172 / 498(34.5)$ & $179 / 504(35.5)$ \\
\hline \multicolumn{7}{|l|}{ Causes of DVT or PE - no. (\%) } \\
\hline Unprovoked & $2713(65.9)$ & $2697(65.4)$ & $1666(67.5)$ & $1655(67.5)$ & $1047(63.5)$ & $1042(62.4)$ \\
\hline Temporary risk factor & $1132(27.5)$ & $1140(27.7)$ & $655(26.5)$ & $655(26.7)$ & 477 (28.9) & $485(29.1)$ \\
\hline Cancer & $378(9.2)$ & $393(9.5)$ & $209(8.5)$ & $205(8.4)$ & $169(10.2)$ & $188(11.3)$ \\
\hline Previous VTE & $784(19.0)$ & $736(17.9)$ & $416(16.9)$ & 414 (16.9) & $368(22.3)$ & $322(19.3)$ \\
\hline
\end{tabular}

* Plus-minus values are means \pm SD. There were no significant differences between the edoxaban group and the warfarin group in any of the characteristics listed here. DVT denotes deep-vein thrombosis, NT-proBNP N-terminal pro-brain natriuretic peptide, PE pulmonary embolism, and VTE venous thromboembolism.

$\uparrow$ Patients with a body weight below $60 \mathrm{~kg}$ or a creatinine clearance of 30 to $50 \mathrm{ml}$ per minute, as well as patients who were receiving concomitant P-glycoprotein inhibitors such as verapamil or quinidine, received $30 \mathrm{mg}$ instead of $60 \mathrm{mg}$ of edoxaban to maintain similar exposure to the cohort receiving $60 \mathrm{mg}$.

Among patients with DVT alone, limited refers to an event in which the most proximal site was the popliteal vein; intermediate, an event in which the most proximal site was the superficial femoral vein; and extensive, an event in which the most proximal site was the common femoral or iliac vein. Among patients with PE, limited refers to involvement of $25 \%$ or less of the vasculature of a single lobe; intermediate, involvement of more than $25 \%$ of the vasculature of a single lobe or multiple lobes with involvement of $25 \%$ or less of the entire vasculature; and extensive, involvement of multiple lobes with $25 \%$ or more of the entire vasculature.

$\int$ Right ventricular function was assessed by calculating the ratio of the right ventricular diameter to the left ventricular diameter on a fourchamber view of the qualifying index pulmonary embolism on a computed tomographic scan.

IA patient could have multiple risk factors. Temporary risk factors included recent surgery, trauma, immobilization, or use of estrogen.

course of recurrent venous thromboembolic events are shown in Table 2 and Figure 2.

The upper limits of the $95 \%$ confidence intervals of the hazard ratios for recurrent venous thromboembolism in patients who presented with deep-vein thrombosis or pulmonary embolism did not exceed the prespecified margin of 1.5 (Table 2). Among patients with pulmonary embolism and evidence of right ventricular dysfunction (NT-proBNP level of $\geq 500$ pg per milliliter), 


\begin{tabular}{|c|c|c|c|c|}
\hline Outcome & $\begin{array}{l}\text { Edoxaban } \\
(\mathrm{N}=4118)\end{array}$ & $\begin{array}{l}\text { Warfarin } \\
(\mathrm{N}=4122)\end{array}$ & $\begin{array}{l}\text { Hazard Ratio with } \\
\text { Edoxaban }(95 \% \mathrm{Cl})\end{array}$ & P Value \\
\hline \multicolumn{5}{|l|}{$\begin{array}{l}\text { Primary efficacy outcome: first recurrent VTE or } \\
\text { VTE-related death - no./total no. (\%) }\end{array}$} \\
\hline \multicolumn{5}{|l|}{ All patients } \\
\hline Event during overall study period & $130 / 4118(3.2)$ & $146 / 4122(3.5)$ & $0.89(0.70-1.13)$ & $\begin{array}{c}<0.001 \\
\text { (for noninferiority) }\end{array}$ \\
\hline Fatal PE & $4 / 4118(0.1)$ & $3 / 4122(0.1)$ & & \\
\hline Death, with PE not ruled out & $20 / 4118(0.5)$ & $21 / 4122(0.5)$ & & \\
\hline Nonfatal PE with or without DVT & $49 / 4118(1.2)$ & $59 / 4122(1.4)$ & & \\
\hline DVT alone & $57 / 4118(1.4)$ & $63 / 4122(1.5)$ & & \\
\hline Event during on-treatment period & $66 / 4118(1.6)$ & $80 / 4122(1.9)$ & $0.82(0.60-1.14)$ & $\begin{array}{c}<0.001 \\
\text { (for noninferiority) }\end{array}$ \\
\hline Patients with index DVT & $2468 / 4118$ (59.9) & $2453 / 4122(59.5)$ & & \\
\hline Event during overall study period & $83 / 2468(3.4)$ & $81 / 2453(3.3)$ & $1.02(0.75-1.38)$ & \\
\hline Event during on-treatment period & $48 / 2468(1.9)$ & $50 / 2453(2.0)$ & $0.96(0.64-1.42)$ & \\
\hline Patients with index PE & $1650 / 4118(40.1)$ & $1669 / 4122(40.5)$ & & \\
\hline Event during overall study period & $47 / 1650(2.8)$ & $65 / 1669(3.9)$ & $0.73(0.50-1.06)$ & \\
\hline Event during on-treatment period & $18 / 1650(1.1)$ & $30 / 1669(1.8)$ & $0.60(0.34-1.08)$ & \\
\hline \multicolumn{5}{|l|}{$\begin{array}{l}\text { Safety outcome during on-treatment period } \\
\qquad- \text { no. (\%) }\end{array}$} \\
\hline $\begin{array}{c}\text { Primary safety outcome: first major or clinically } \\
\text { relevant nonmajor bleeding }\end{array}$ & $349(8.5)$ & $423(10.3)$ & $0.81(0.71-0.94)$ & $\begin{array}{l}0.004 \\
\text { (for superiority) }\end{array}$ \\
\hline Major bleeding & $56(1.4)$ & $66(1.6)$ & $0.84(0.59-1.21)$ & $\begin{array}{c}0.35 \\
\text { (for superiority) }\end{array}$ \\
\hline Fatal & $2(<0.1)$ & $10(0.2)$ & & \\
\hline Intracranial & 0 & $6(0.1)$ & & \\
\hline Gastrointestinal & $1(<0.1)$ & $2(<0.1)$ & & \\
\hline Retroperitoneal & 0 & $1(<0.1)$ & & \\
\hline Other & $1(<0.1)$ & $1(<0.1)$ & & \\
\hline Nonfatal in critical site & $13(0.3)$ & $25(0.6)$ & & \\
\hline Intracranial & $5(0.1)$ & $12(0.3)$ & & \\
\hline Retroperitoneal & 0 & $3(0.1)$ & & \\
\hline Other & $8(0.2)$ & $10(0.2)$ & & \\
\hline Nonfatal in noncritical site & $41(1.0)$ & $33(0.8)$ & & \\
\hline Clinically relevant nonmajor bleeding & $298(7.2)$ & $368(8.9)$ & $0.80(0.68-0.93)$ & $\begin{array}{l}0.004 \\
\text { (for superiority) }\end{array}$ \\
\hline Any bleeding & $895(21.7)$ & $1056(25.6)$ & $0.82(0.75-0.90)$ & $\begin{array}{l}\quad<0.001 \\
\text { (for superiority) }\end{array}$ \\
\hline \multicolumn{5}{|l|}{ Other adverse event — no. (\%) } \\
\hline $\begin{array}{c}\text { Any adverse event occurring during } \\
\text { on-treatment period }\end{array}$ & $2821(68.5)$ & $2928(71.0)$ & & \\
\hline Any serious adverse event & $503(12.2)$ & $544(13.2)$ & & \\
\hline $\begin{array}{c}\text { Any serious adverse event leading to permanent dis- } \\
\text { continuation of the study drug }\end{array}$ & $121(2.9)$ & $105(2.5)$ & & \\
\hline $\begin{array}{c}\text { Any drug-related adverse event leading to permanent } \\
\text { discontinuation of the study drug }\end{array}$ & $41(1.0)$ & $51(1.2)$ & & \\
\hline
\end{tabular}

* The primary efficacy and safety outcomes were assessed by means of time-to-first-event analyses. Patients could have more than one event. The overall study period was 12 months; the on-treatment period included the time during which the patients were receiving the study drug or within 3 days after the study drug was stopped or interrupted.

The New England Journal of Medicine 


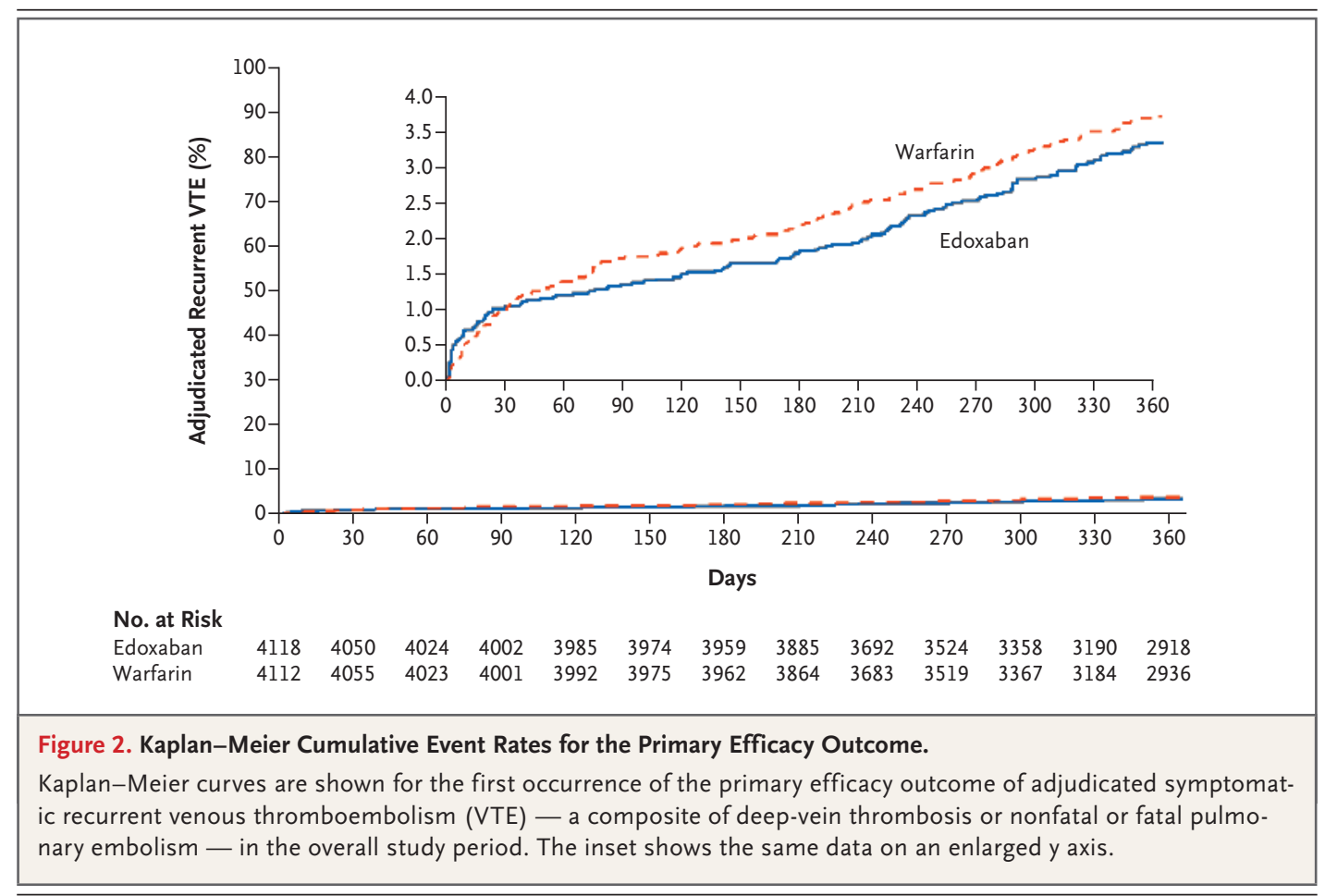

recurrent venous thromboembolism occurred in 15 of 454 patients (3.3\%) in the edoxaban group and in 30 of 484 patients $(6.2 \%)$ in the warfarin group (hazard ratio, $0.52 ; 95 \%$ CI, 0.28 to 0.98 ). Similar results were observed among patients with right ventricular dysfunction as assessed by means of computed tomography (hazard ratio, 0.42 ; $95 \% \mathrm{CI}, 0.15$ to 1.20 ).

Among patients who qualified for the 30-mg dose of edoxaban, recurrent venous thromboembolism occurred in 22 of 733 patients (3.0\%) receiving edoxaban, as compared with 30 of the 719 patients $(4.2 \%)$ receiving warfarin (hazard ratio, 0.73 ; $95 \% \mathrm{CI}, 0.42$ to 1.26 ). The hazard ratios for recurrent venous thromboembolism in the other prespecified subgroups are shown in Figure S1 in the Supplementary Appendix.

\section{BLEEDING OUTCOMES}

Clinically relevant bleeding (major or nonmajor) occurred in 349 of 4118 patients (8.5\%) in the edoxaban group and in 423 of 4122 patients $(10.3 \%)$ in the warfarin group (hazard ratio, 0.81; $95 \% \mathrm{CI}, 0.71$ to $0.94 ; \mathrm{P}=0.004$ for superiority). The difference in risk (edoxaban minus warfarin) was -1.8 percentage points $(95 \% \mathrm{CI},-3.04$ to $-0.53)$. Major bleeding occurred in 56 patients
(1.4\%) in the edoxaban group and in 66 patients $(1.6 \%)$ in the warfarin group (hazard ratio, 0.84; $95 \% \mathrm{CI}, 0.59$ to 1.21$)$. The clinical presentation and time course of bleeding events are provided in Table 2 and Figure 3.

Among patients who qualified for the 30-mg dose of edoxaban, clinically relevant bleeding occurred in 58 of 733 patients (7.9\%) who received edoxaban, and in 92 of the 719 patients $(12.8 \%)$ who received warfarin (hazard ratio, 0.62 ; $95 \%$ CI, 0.44 to 0.86 ). Major bleeding occurred in 11 patients $(1.5 \%)$ in the edoxaban group and in 22 patients (3.1\%) in the warfarin group (hazard ratio, 0.50 ; $95 \%$ CI, 0.24 to 1.03 ). The hazard ratios for bleeding in the other prespecified subgroups are provided in Figure S2 in the Supplementary Appendix.

\section{DEATHS AND OTHER ADVERSE EVENTS}

The number and causes of death, as well as results with respect to the net clinical benefit, are shown in Table S3 in the Supplementary Appendix. There were 21 acute coronary events in the edoxaban group ( $0.5 \%)$ and 16 in the warfarin group $(0.4 \%)$. The rates of other adverse outcomes were also similar in the two groups. (Table 2, and Table S3 in the Supplementary Appendix). 


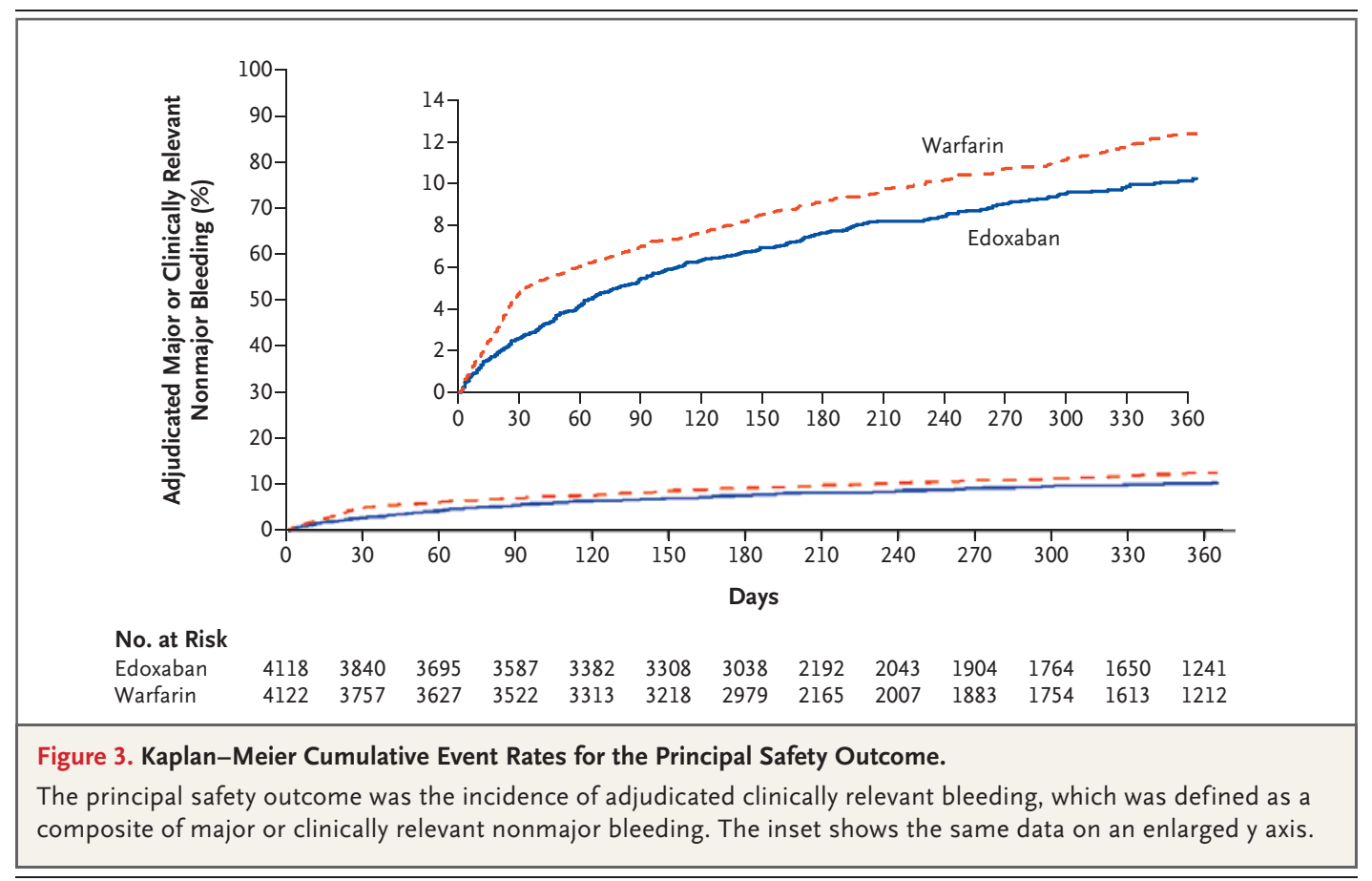

\section{DISCUSSION}

In this large, double-blind study involving patients with venous thromboembolism, treatment with heparin followed by oral edoxaban once daily, as compared with standard therapy, was noninferior with respect to efficacy and superior with respect to bleeding. We succeeded in enrolling patients across a broad spectrum of venous thromboembolic manifestations, ranging from limited proximal deep-vein thrombosis to severe pulmonary embolism, and the relative efficacy was observed throughout. In analyses of safety, the results were consistent with respect to both major bleeding and clinically relevant nonmajor bleeding, with fewer fatal and intracranial bleeds in the edoxaban group (Table 2), although the between-group difference with respect to major bleeding did not reach statistical significance.

Efficacy was evaluated at 12 months of follow-up, regardless of the duration of treatment - a study design that was different from that of earlier studies. ${ }^{5-8}$ The design of the Hokusai-VTE study, as compared with a design calling for ontreatment analyses only, allowed for a better understanding of the outcomes that may be expected in clinical practice. In the on-treatment analysis, we observed low rates of recurrence that were similar to those seen in contemporary studies. ${ }^{5-8}$ In our study, the relative efficacy of edoxaban was not limited to patients receiving medication, but it was evident even among those who stopped treatment before 12 months (Fig. 2).

Some aspects of our trial warrant comment. Three recent studies focused on a single-drug approach for all treatment phases. ${ }^{6-8}$ Thus, the use of the traditional sequence of a heparin leadin followed by an oral agent may be considered a limitation of the Hokusai-VTE study. However, given the global acceptance of, and confidence in, initial parenteral treatment, the heparin lead-in encouraged investigators to enroll a high proportion of patients with severe grades of venous thromboembolism. When designing the study, we anticipated that a considerable proportion of patients with right ventricular dysfunction due to pulmonary embolism would be included. We measured NT-proBNP levels in all patients with pulmonary embolism and assessed right ventricular dimensions by means of computed tomography in a random subgroup of 1002 of these patients. Approximately one third had right ventricular dysfunction. There was a reduction in recurrences among patients with elevated NT-proBNP levels in the edoxaban group, and this finding was supported by the analysis of 
patients with right ventricular dysfunction as assessed by means of computed tomography.

The study design aimed to address concerns that new oral anticoagulants may confer a higher risk of bleeding among patients with renal impairment and low body weight. ${ }^{12}$ We identified approximately one fifth of patients with these risk factors. Halving of the daily dose of edoxaban to $30 \mathrm{mg}$ maintained efficacy with significantly less bleeding than that observed in the warfarin group.

To ensure best practice with the comparator, the quality of warfarin therapy was proactively monitored throughout the study. This resulted in an overall time in the therapeutic range of $63.5 \%$, which is a higher percentage of time in the therapeutic range than the 40 to $50 \%$ seen in registries of clinical practice. ${ }^{20-22}$ Our findings are likely to be generalizable. In this global study, we included patients with both provoked and unprovoked venous thromboembolism, and treatment durations varied from 3 to 12 months at the discretion of the treating physician. Loss to follow-up was very low $(<0.2 \%)$, as was the rate of withdrawal of consent $(<0.9 \%) .^{23}$

In conclusion, the Hokusai-VTE study showed that in a broad spectrum of patients with venous thromboembolism, including those with severe pulmonary embolism, edoxaban administered once daily after initial heparin was noninferior to standard therapy with warfarin after initial heparin, with significantly less bleeding.

\section{Supported by Daiichi-Sankyo.}

Dr. Büller reports receiving consulting fees from Bayer, Boehringer Ingelheim, Bristol-Myers Squibb, Isis Pharmaceuticals, and ThromboGenics, and grant support from Bayer and Pfizer. Dr. Décousus reports receiving fees for board membership from Bayer and Daiichi Sankyo, lecture fees from GlaxoSmithKline, and grant support from Bayer, Bristol-Myers Squibb-Pfizer, Boehringer Ingelheim, and Portola. Drs. Grosso, Mercuri, Schwocho, and Shi report being employees of Daiichi Sankyo. Dr. Middeldorp reports receiving consulting fees from Bayer and Bristol-Myers Squibb-Pfizer, lecture fees from Bayer, GlaxoSmithKline, BristolMyers Squibb-Pfizer, and Boehringer Ingelheim, and grant support from GlaxoSmithKline, Bristol-Myers Squibb-Pfizer, and Sanquin. Dr. Prins reports receiving consulting fees from Bayer, Pfizer, and Boehringer Ingelheim, and lecture fees from Bayer. Dr. Raskob reports receiving consulting fees and travel support from Bayer, Bristol-Myers Squibb, Janssen, Johnson \& Johnson, Pfizer, SanofiAventis, and Takeda. Dr. Schellong reports receiving consulting fees from Bayer and Boehringer Ingelheim, and lecture fees from Bayer, Boehringer Ingelheim, and Bristol-Myers Squibb-Pfizer. Dr. Segers reports receiving fees for the scientific management of the studies as director of the International Clinical Trial Organization and Management (ICTOM) academic research organization from Bayer, Isis Pharmaceuticals, and Pfizer. Dr. Verhamme reports receiving consulting fees from Bayer, Boehringer Ingelheim, ThromboGenics, and Pfizer, lecture fees from Bayer, Boehringer Ingelheim, Leo Pharma, Sanofi-Aventis, and Pfizer, and grant support from Bayer, Boehringer Ingelheim, Leo Pharma, and Sanofi-Aventis. Dr. Wells reports receiving lecture fees from Bayer, Boehringer Ingelheim, Biomerieux, and Bristol-Myers SquibbPfizer. No other potential conflict of interest relevant to this article was reported.

Disclosure forms provided by the authors are available with the full text of this article at NEJM.org.

We thank Sunny Cho, Min Lin, Gregg Lovelace, and George Zhang for their assistance in the analyses and manuscript preparation.

APPENDIX

The affiliations of the members of the writing committee are as follows: the Department of Vascular Medicine, Academic Medical Center, University of Amsterdam, Amsterdam (H.R.B., S.M.); INSERM CIE3, University of Saint Etienne, Centre Hospitalier Universitaire, Saint-Etienne, France (H.D.); Daiichi Sankyo Pharma Development, Edison, NJ (M.A.G., M.M., L.S., M.S.); the Department of Epidemiology, Care and Public Health Research Institute, Maastricht University Medical Center, Maastricht, the Netherlands (M.H.P.); University of Oklahoma Health Sciences Center, College of Public Health, Oklahoma City (G.E.R.); Municipal Hospital Friedrichstadt, Dresden, Germany (S.M.S.); International Clinical Trial Organization and Management academic research organization, Amsterdam (A.S.); the Department of Vascular Medicine and Hemostasis, University Hospitals Leuven, Leuven, Belgium (P.V.); and the Department of Medicine, University of Ottawa and Ottawa Hospital Research Institute, Ottawa (P.W.).

REFERENCES

1. Heit JA. The epidemiology of venous thromboembolism in the community: implications for prevention and management. J Thromb Thrombolysis 2006;21:23-9.

2. White RH. The epidemiology of venous thromboembolism. Circulation 2003;107: Suppl 1:I-4-I-8.

3. Goldhaber SZ, Bounameaux H. Pulmonary embolism and deep vein thrombosis. Lancet 2012;379:1835-46.

4. Kearon C, Akl EA, Comerota AJ, et al. Antithrombotic therapy for VTE disease: Antithrombotic Therapy and Prevention of Thrombosis, 9th ed: American College of Chest Physicians evidence-based clinical practice guidelines. Chest 2012;141:Suppl: e419S-e494S. [Erratum, Chest 2012;142 1698-704.]

5. Schulman S, Kearon C, Kakkar AK, et al. Dabigatran versus warfarin in the treatment of acute venous thromboembolism. N Engl J Med 2009;361:2342-52.

6. The EINSTEIN Investigators. Oral rivaroxaban for symptomatic venous thromboembolism. N Engl J Med 2010;363:2499-510. 7. The EINSTEIN-PE Investigators. Oral rivaroxaban for the treatment of symptomatic pulmonary embolism. N Engl J Med 2012;366:1287-97.

8. Agnelli G, Buller HR, Cohen A, et al.
Oral apixaban for the treatment of acute venous thromboembolism. N Engl J Med 2013;369:799-808.

9. Fuji T, Fujita S, Tachibana S, Kawai Y. A dose-ranging study evaluating the oral factor Xa inhibitor edoxaban for the prevention of venous thromboembolism in patients undergoing total knee arthroplasty. J Thromb Haemost 2010;8:2458-68. 10. Raskob G, Cohen AT, Eriksson BI, et al. Oral direct factor Xa inhibition with edoxaban for thromboprophylaxis after elective total hip replacement: a randomised double-blind dose-response study. Thromb Haemost 2010;104:642-9. 
11. Weitz JI, Connolly SJ, Patel I, et al. Randomised, parallel-group, multicentre, multinational phase 2 study comparing edoxaban, an oral factor Xa inhibitor, with warfarin for stroke prevention in patients with atrial fibrillation. Thromb Haemost 2010;104:633-41.

12. Raskob G, Büller $H$, Prins $M$, et al. Edoxaban for the long-term treatment of venous thromboembolism: rationale and design of the Hokusai-VTE study - methodological implications for clinical trials. J Thromb Haemost 2013;11:1287-94.

13. Schulman S, Kearon C. Definition of major bleeding in clinical investigations of antihemostatic medicinal products in non-surgical patients. J Thromb Haemost 2005;3:692-4.

14. The van Gogh Investigators. Idraparinux versus standard therapy for venous thromboembolic disease. N Engl J Med 2007;357:1094-104.

15. Rosendaal FR, Cannegieter SC, van der Meer FJ, Briët E. A method to determine the optimal intensity of oral anticoagulant therapy. Thromb Haemost 1993; 69:236-9.

16. Sanchez O, Trinquart L, Colombet I, et al. Prognostic value of right ventricular dysfunction in patients with haemodynamically stable pulmonary embolism: a systematic review. Eur Heart J 2008;29: 1569-77.

17. Lega JC, Lacasse Y, Lakhal L, Provencher S. Natriuretic peptides and troponins in pulmonary embolism: a metaanalysis. Thorax 2009;64:869-75.

18. Furlan A, Aghayev A, Chang CC, et al. Short-term mortality in acute pulmonary embolism: clot burden and signs of right heart dysfunction at CT pulmonary angiography. Radiology 2012;265:283-93.

19. Lu MT, Demehri S, Cai T, et al. Axial and reformatted four-chamber right ventricle-to-left ventricle diameter ratios on pulmonary CT angiography as predictors of death after acute pulmonary embolism. AJR Am J Roentgenol 2012;198:1353-60. 20. Deitelzweig SB, Lin J, Kreilick C, Hussein $\mathrm{M}$, Battleman D. Warfarin therapy in patients with venous thromboembolism: patterns of use and predictors of clinical outcomes. Adv Ther 2010;27:623-33.

21. Willey VJ, Bullano MF, Hauch O, et al. Management patterns and outcomes of patients with venous thromboembolism in the usual community practice setting. Clin Ther 2004;26:1149-59.

22. Wallentin L, Yusuf S, Ezekowitz MD, et al. Efficacy and safety of dabigatran compared with warfarin at different levels of international normalised ratio control for stroke prevention in atrial fibrillation: an analysis of the RE-LY trial. Lancet 2010; 376:975-83.

23. Fleming TR. Addressing missing data in clinical trials. Ann Intern Med 2011; 154:113-7.

Copyright (c) 2013 Massachusetts Medical Society.

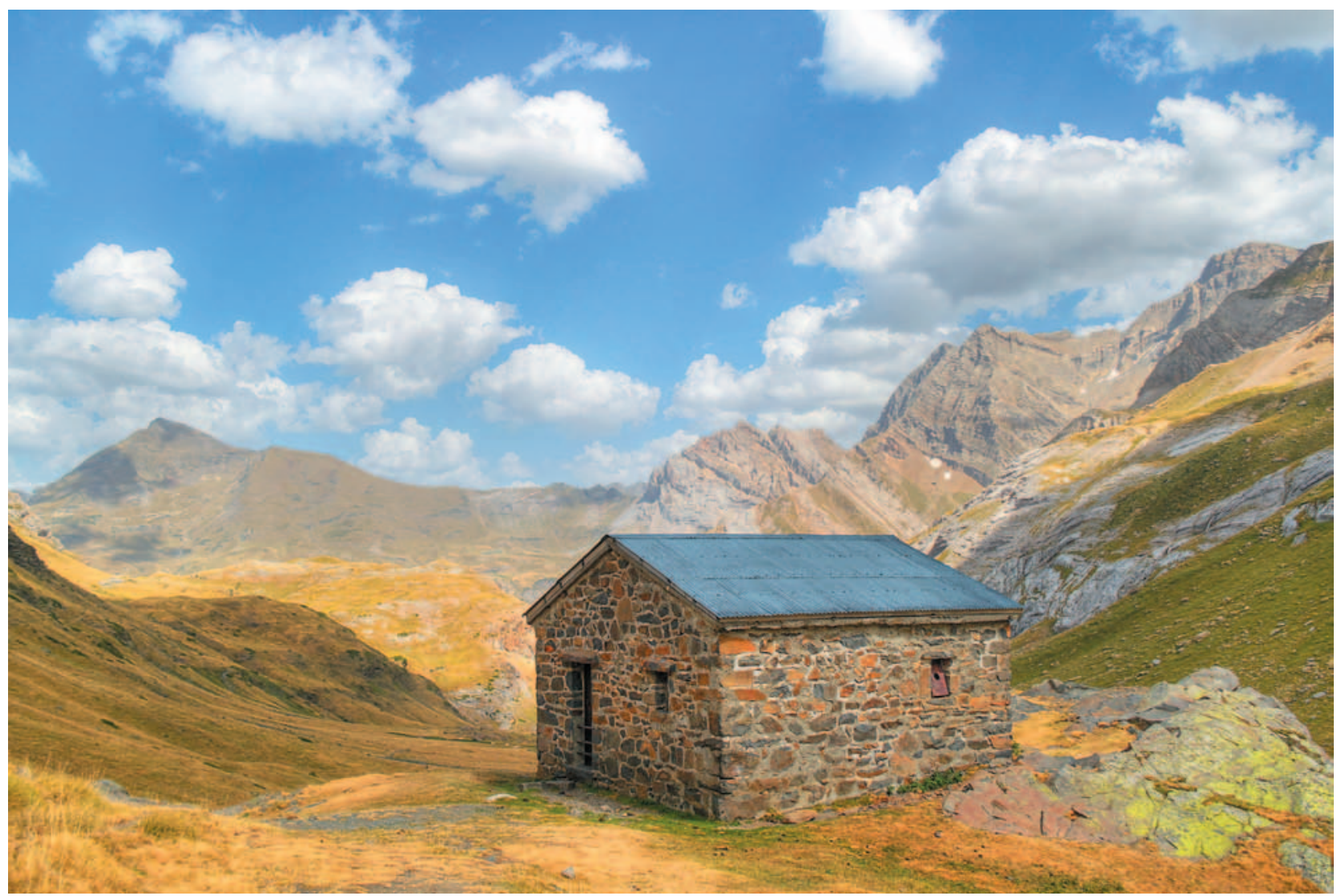

Shepherd Hut in the Pyrenees, Spain

Avital Hershkovitz, M.D.

The New England Journal of Medicine 